\title{
MEMÓRIA DO PROGRAMA “TRILHAS POTIGUARES” (1996-1999): 23 ANOS DEPOIS
}

\author{
Andréia da Silva Quintanilha Sousa ${ }^{1}$ \\ https://orcid.org/0000-0002-4540-4020
}

Resumo: Este artigo revisita a atividade de extensão denominada "Trilhas Potiguares" desenvolvida na Universidade Federal do Rio Grande do Norte (UFRN). Essa atividade foi objeto da pesquisa intitulada "Memória do Programa Trilhas Potiguares de 1996-1999". A pesquisa de natureza qualitativa visava, dentre outros objetivos, preservar a memória dessa atividade de extensão e foi realizada em nível de mestrado no Programa de Pós-graduação em Educação da UFRN entre os anos 1998 a 2000. Hoje, o Programa Trilhas Potiguares está na sua vigésima terceira edição e é considerado o "maior Programa de Extensão" da UFRN conforme Fraga e Villa (2017). O Relatório das Trilhas Potiguares do ano de 2018 divulga que o Programa envolve 243 alunos, 43 cursos, 11 Centros, desenvolve 743 ações e 29.886 pessoas foram atendidas pelo programa (UFRN, 2019b). Passadas mais de duas décadas da realização da pesquisa, é possível afirmar que as atividades de extensão do Trilhas preservam os aspectos positivos identificados naquele estudo realizado há vinte anos: a sua capacidade de articular ensino e extensão. Porém, acompanha a tendência mundial que convoca as universidades a assumirem o protagonismo no processo de desenvolvimento da sociedade, nos campos científicos, social, econômico, ambiental e cultural nos marcos da racionalidade neoliberal.

Palavras-chave: Memória. Extensão. Programa Trilhas Potiguares.

\section{MEMORY OF THE “TRILHAS POTIGUARES” PROGRAM (1996-1999): 23 YEARS LATER}

\begin{abstract}
This article revisits the extension activity called "Trilhas Potiguares" developed at the Federal University of Rio Grande do Norte (UFRN). This activity was the object of the research entitled "Memory of the Trilhas Potiguares Program of 1996-1999". Qualitative research aimed, among other objectives, to preserve the memory of this extension activity and was carried out at a master's level in the Post-Graduation Program in Education of UFRN between 1998 and 2000. Today the Trilhas Potiguares Program is in the its twenty-third edition and is considered the largest extension program of UFRN according to Fraga and Villa (2017). The 2018 reports state that the Program involves 243 students, 43 courses, 11 Centers, develops 743 actions and

1 Doutora em educação pela Universidade Federal do Rio Grande do Norte (UFRN) e Pós-Doutora na Universidade de Algarve/PT; professora da Universidade Federal do Rio Grande do Norte. E-mail: aquintanilhasousa|@gmail.com.
\end{abstract}


29,886 people were served by the program (UFRN, 2019b). After more than two decades of research, it is possible to affirm that the activities of extension of the Trilhas preserve the positive aspects identified in that study realized twenty years ago: its capacity to articulate teaching and extension. However, it accompanies the worldwide trend that calls universities to take the lead in the process of development of society in the scientific, social, economic, environmental and cultural fields within the framework of neoliberal rationality.

Keywords: Memory. Extension. Trails Potiguares Program

\section{MEMORIA DEL PROGRAMA “TRILHAS POTIGUARES” (1996-1999): 23 AÑOS DESPUÉS}

Resumen: Este artículo revisita la actividad de extensión denominada "Trilhas Potiguares" desarrollada en la Universidad Federal de Rio Grande do Norte (UFRN). Esta actividad fue objeto de la investigación titulada "Memoria del Programa Trilhas Potiguares de 19961999”. La investigación de naturaleza cualitativa pretendía, entre otros objetivos, preservar la memoria de esa actividad de extensión y fue realizada a nivel de maestría en el Programa de Postgrado en Educación de la UFRN entre los años 1998 a 2000. Hoy, el Programa Trilhas Potiguares está en la su vigésima tercera edición y es considerado el "mayor Programa de Extensión” de la UFRN según Fraga y Villa (2017). El Informe de las Trilhas Potiguares del año 2018 divulga que el Programa involucra a 243 alumnos, 43 cursos, 11 Centros, desarrolla 743 acciones y 29.886 personas fueron atendidas por el programa (UFRN, 2019b). En el transcurso de más de dos décadas de la realización de la investigación, es posible afirmar que las actividades de extensión de las Rutas preservan los aspectos positivos identificados en aquel estudio realizado hace veinte años: su capacidad de articular enseñanza y extensión. Sin embargo, acompaña la tendencia mundial que convoca a las universidades a asumir el protagonismo en el proceso de desarrollo de la sociedad, en los campos científico, social, económico, ambiental y cultural en los marcos de la racionalidad neoliberal.

Palabras clave: Memoria. Extensión. Programa Trilhas Potiguares.

Submetido em: 10/10/2018

Aceito em: 01/11/2018

\section{PROGRAMA TRILHAS POTIGUARES E A SUA INSPIRAÇÃO NO PROJETO “PÉ NA TRILHA"}

O Programa Trilhas Potiguares tem a sua primeira Edição no ano de 1996 tendo como fonte de inspiração o Projeto "Pé na Trilha”, que surgiu em 1990 como resultado do Encontro Regional dos Estudantes de Geografia do Nordeste (EREGEN), realizado no estado do Piauí. Durante esse evento, os alunos da Universidade Federal do Rio Grande do Norte conheceram um grupo de alunos do curso de Geografia, da Universidade Federal da Paraíba, que desenvolvia uma caminhada denominada "Pé na Trilha". Tratava-se de uma 
caminhada informal saindo de João Pessoa a Cabedelo sem finalidade de pesquisa (CARVALHO, 1999).

Segundo Sousa (2000) alicerçada nas informações coletadas de Queiroga (1999) a ideia de fazer caminhadas no Rio Grande do Norte partiu de um aluno que procurou um professor de cartografia, do Departamento de Geografia, e juntos solicitaram ajuda para viabilizar o projeto na UFRN. Segundo afirma Queiroga (1999 apud SOUSA, 2000, p. 64),

Não havia aqui, pelo menos que eu conhecesse, um projeto assim. Eu sugeri que procurássemos o professor Edilson que nos tínhamos mais acesso e afinidade de conversar. Ele trouxe mapas e sugeriu o primeiro percurso da caminhada. A ideia era aplicar o que aprendíamos na sala de aula na caminhada, pois na sala de aula, o que se vê é muita teoria [...] é muito diferente do que se vê lá fora. A teoria é uma e a prática é outra. No início, conhecer a realidade do litoral e depois o interior do nosso estado e, se fosse possível fazer o retorno, ver o que tinha ocorrido com a população e o meio ambiente, pois a Geografia abrange esses dois lados. Foi uma oportunidade de sair dos muros da Universidade. Havia preocupação com o impacto ambiental.

O professor mencionado anteriormente relata como foram feitos os primeiros encaminhamentos para pôr em prática a iniciativa dos alunos. Segundo o seu depoimento, quando soube da ideia dos discentes de criar no Rio Grande do Norte o Projeto "Pé na Trilha", desenvolvido na Paraíba, ficou "totalmente entusiasmado". Eis o que ele afirma:

[...] quando soube da notícia, fiquei totalmente entusiasmado. No mesmo momento, larguei o que estava fazendo e fui com eles à sala de cartografia e começamos a organizar. Trouxe os mapas e parecia que até já sabíamos aonde iríamos. De repente, começamos a divulgar a ideia. Isto foi em outubro de noventa, começamos a organizar para fazer nas férias, mais ou menos janeiro ou fevereiro. $\mathrm{O}$ fato é que, através do Centro Acadêmico e com o meu apoio como professor (os alunos sentem a necessidade do professor à frente das iniciativas), nós organizamos dentro de um período curto de tempo, conseguimos patrocínio para camisetas, alimentos em supermercados, fizemos uma campanha, mobilizamos boa parte dos alunos. Tivemos um total de 39 pessoas inscritas. E essa caminhada saiu depois do Cajueiro de Pirangi no dia 19 de janeiro de 1991, chegando à Baia Formosa no dia 21 de janeiro. Em três dias, um total de $60 \mathrm{~km}$. A primeira parada foi em Barreta, segundo dia em Pipa, na casa de um aluno que estava na caminhada conosco; o terceiro dia em Baía Formosa. Quase tudo foi feito com recursos próprios [...] (CARVALHO, 1999).

Podemos constatar por meio das entrevistas realizadas que os participantes do Projeto consideravam a atividade importante no processo de formação. 
As atividades do "Pé na Trilha" estão mais ligadas ao ensino, como se fossem uma aula de campo. Seu objetivo primeiro é vivenciar na prática os conhecimentos adquiridos em sala de aula. Esse Projeto inspirou o Programa Trilhas Potiguares, como se pode apreender dos depoimentos a seguir:

Em 1995, quando a gente começou a ter essa ideia, a gente conhecia o Pé-na-Trilha, que na realidade era uma iniciativa dos alunos de Geografia que sentindo falta de trabalhos, de aulas de campo, resolveram formar grupos e convidaram professores para orientá-los em viagem de campo. A gente resolveu, conhecendo esta iniciativa do Centro Acadêmico de Geografia, convidar os alunos e professores da Geografia para conversar e ver de que maneira nós podíamos levar esta ideia para toda a universidade. O professor Telésforo que foi o idealizador dessa ideia das Trilhas [...] (MEDEIROS 2000 apud SOUSA, 2000, p. 63).

O depoimento do Pró-Reitor de Extensão, Professor Arnon Alberto Mascarenhas de Andrade, denota que o desejo de estender o Projeto "Pé na Trilha" para toda a universidade. Contudo, não foi possível porque "os alunos não quiseram ceder o nome Pé na Trilha". Assim, diante da negativa dos alunos de cederem o nome, o Professor Telésforo Nóbrega de Medeiros, que assumiu o Departamento de Extensão de 29 de maio de 1995 a 5 de maio de 1997, deu o nome Trilhas Potiguares ao Projeto. Os idealizadores do Trilhas Potiguares reconhecem a inspiração que lhes causou o Projeto "Pé na Trilha", mas deixam claro que o "Trilhas Potiguares têm identidade própria" (SOUSA, 2000, p.69).

Dessa forma, o Programa Trilhas Potiguares é apresentado como uma iniciativa inovadora da UFRN para

verticalizar experiências de atuação em comunidades, associando-se-lhes referenciais de continuidade, pertinência e acompanhamento sistemático da ação integradora entre a Universidade e a Comunidade Potiguar, sem perder de vista a sua universalidade, a nova ordem econômica mundial, os avanços tecnológicos e os paradigmas contemporâneos, entre os quais o da ética (UFRN, 1999, p. 6).

Através dos documentos elaborados pela Pró-Reitoria de Extensão da UFRN, é possível perceber a preocupação da instituição em ampliar a melhoria dos indicadores da educação e saúde pública através da cooperação conjunta entre a Universidade Federal do Rio Grande do Norte, o Governo do estado do $\mathrm{RN}$ e as prefeituras municipais. Para tanto, procura-se ampliar os programas de intercâmbio com o estado, as empresas e a sociedade civil a fim de "encontrar 
parceiros, descobrir caminhos, comprometer-se com o desenvolvimento, a justiça, o meio ambiente, a reflexão ética (UFRN, 1995, p. 19).

Assim, no ano de 1996, têm início as primeiras atividades do Trilhas Potiguares. As atividades desenvolveram-se na região mais seca do estado do $\mathrm{RN}$ e participaram 300 pessoas. As equipes permaneceram nos municípios durante três dias em dois finais de semana $(18,19,20,24,25$ e 26 de maio de 1996), conforme Sousa (2000).

Segundo depoimento concedido a nossa pesquisa, a coordenadora do Programa à época, Sra. Márjorie da Fonseca e Silva Medeiros, explicou que a ideia inicial de caminhadas, conforme ocorriam no Projeto "Pé na Trilha", não era a única forma de trabalho a ser adotada pelas equipes a partir de então. Vejamos o seu depoimento:

\footnotetext{
No primeiro ano [1996] a gente fez dois momentos de Trilhas. Tinham [duas equipes], uma que ainda seguia um pouco a metodologia do Pé-na-Trilha, [ousej], equipes que andavam [...] a pé de uma cidade a outra, e tinham grupos de ação comunitária nas cidades $\{\mathrm{A}$ primeira\} vendo os aspectos físicos, geográficos, geológicos dos locais por onde passavam com professores dando aula, eram equipes multidisciplinares, não iam só alunos de Geografia, mas na realidade você só estava colhendo, não estava deixando nada para a cidade, ao contrário daquelas outras equipes que estavam desenvolvendo ações nas comunidades. E, foi exatamente esta equipe que vingou. Tanto é que, em 1997, se abandonou completamente a ideia de caminhar. A gente viu que as Trilhas tinham que ser ação comunitária, ação de desenvolvimento na comunidade, abandonamos a ideia de andar de uma cidade a outra apenas colhendo e realmente passou para a ideia de plantar semente (MEDEIROS, 2000 apud SOUSA, 2000, p. 74).
}

As universidades podem responder a tais desafios, assumindo o papel de impulsionador das políticas públicas no processo de desenvolvimento das pessoas e da sociedade a partir dos conhecimentos nela gerados? Ainda, na sua tríplice missão de realizar ensino, pesquisa e extensão, já não "planta as sementes" que colaboram na construção da sociedade? Há por parte do Programa, já na sua concepção, um esforço para a integração das três atividades-fim da universidade? Ou é possível inferir a existência de uma atitude de desvalorização de posturas investigativas que não estejam articuladas com a demanda específica?

Os primeiros anos do Programa Trilhas denotam a preocupação de atender às demandas dos municípios, de acordo com a tendência de convocar as IES a contribuírem, conforme afirmam Bonhemberger e Audy (2018, p. 67), "para o crescimento das nações". De fato, as IES 
são convidadas a constantemente revisitar suas origens para que não se distanciem de seu propósito inicial de um ensino, voltado à formação de profissionais que, comprometidos com o desenvolvimento da comunidade humana local, regional e global, possam fazer uso consciente de seu exercício cidadão (BONHEMBERGER; AUDY, 2018, p. 67).

Esses discursos emergem a partir da segunda metade dos anos 1980, momento que um novo quadro de forças traz os discursos sobre a universidade pública, elaborado basicamente por três atores principais - movimento docente organizado através da Associação Nacional de Docentes do Ensino Superior (ANDES), dirigentes universitários representados pelo Conselho de Reitores das Universidades Brasileiras (CRUB) e governo - colocaram em destaque novas formas de conceber a universidade, cuja relação com a sociedade sinalizava para a necessidade de concretização de uma nova ação política que privilegiasse camadas mais amplas da população historicamente marginalizadas (SOUSA, 2000).

Tavares (1997) afirma que é nesse contexto que começa a delinear-se a concepção de universidade dentro de um projeto político global, que veicula democratização com a necessidade de relacionamento com a sociedade.

Nesse passo, a extensão passa a ser entendida como articuladora do ensino e da pesquisa, vinculando-se ao exercício de transformação da sociedade através do contato direto, realimentador e recíproco entre professores, alunos, técnicos, administradores e população.

As conclusões dos intelectuais sobre a nova concepção de extensão universitária aprovada no I Encontro Nacional de Associações Docentes (ENAD) denotam que o caráter de terceira função é retirado e passam a direcioná-la como política estratégica, sinalizando para uma universidade voltada aos problemas sociais, visando realimentar o processo ensino-aprendizagem como um todo e intervindo na realidade concreta.

É dentro desse contexto de redemocratização que o recém-criado Fórum de Pró-Reitores de Extensão passa a reivindicar uma participação efetiva na gestão da política de extensão universitária a ser implementada institucionalmente, defendendo maior autonomia na execução das atividades institucionais.

Nos anos 1990, assistimos às propostas da Reforma do Aparelho do Estado baseadas no diagnóstico, que aponta como um dos principais problemas a rigidez decorrente da aplicação generalizada de normas burocráticas nos setores em que elas são consideradas desnecessárias. Considerando tais tendências, o 
Estado, através do Ministério da Administração Federal e Reforma do Estado (MARE), defende ideias de "privatização", "publicização" e "terceirização", bem como formas de administração que superem a burocrática para um tipo de administração gerencial (SOUSA, 2000).

É nesse contexto que, em abril de 1999, foi elaborado pelo Fórum de PróReitores de Extensão das Universidades Públicas brasileiras e pela Secretaria do Ensino Superior do MEC o Plano Nacional de Extensão. Esse Plano afirma o compromisso da Universidade com a transformação da sociedade, a justiça, a solidariedade e a democracia e define extensão como atividade acadêmica capaz de imprimir um novo rumo à Universidade Brasileira e de construir significativamente para a mudança da sociedade, pois acreditam que as universidades públicas brasileiras "são instituições criadas para atender às necessidades do país [...] associadas ao desenvolvimento econômico, social, cultural e político da Nação" e defendem que "são espaços privilegiados para a produção e acumulação do conhecimento e a formação de profissionais cidadãos" (SOUSA, 2000, p. 36).

Esse Plano defende a construção de Planos Regionais e Institucionais que tomem por base a delimitação do perfil geopolítico de cada região e a indicação das demandas sociais. Assim, o reconhecimento legal da atividade de extensão, sua inclusão na Constituição e a organização do Fórum de Pró-Reitores de Extensão, no fim da década de 1980, imprimiram as condições e o lugar para uma conceituação da extensão universitária, assim expressa no I Encontro Nacional de Pró-Reitores de Extensão. Encontro realizado na Universidade de Brasília, nos dias 4 e 5 de novembro de 1987, em que participaram 22 universidades públicas representadas por seus pró-reitores ou ocupantes de cargo similar nas instituições. Extensão Universitária, conforme as conclusões aprovadas nas sessões plenárias do Encontro, é o

[...] processo educativo, cultural e científico que articula o Ensino e a Pesquisa de forma indissociável e viabiliza a relação transformadora entre universidade e sociedade. A Extensão é uma via de mão dupla, com trânsito assegurado à comunidade acadêmica, que encontrará, na sociedade, a oportunidade de elaboração da práxis de um conhecimento acadêmico. No retorno à Universidade, docentes e discentes trarão um aprendizado que, submetido à reflexão teórica, será acrescido àquele conhecimento. Esse fluxo, que estabelece a troca de saberes sistematizados, acadêmico e popular terá como consequência: a produção do conhecimento resultante do confronto com a realidade brasileira e regional; a democratização do conhecimento acadêmico e a participação efetiva da comunidade na atuação da Universidade. Além 
de instrumentalizadora desse processo dialético de teoria/prática, a Extensão é um trabalho interdisciplinar que favorece a visão integrada do social (PLANO..., 2019).

A conceituação anteriormente expressa denota a compreensão que tinham acerca da função básica da universidade diante da sociedade em que se insere, qual seja: o "de produção e de socialização do conhecimento, visando a intervenção, na realidade", possibilitando assim, "acordos e ação coletiva entre universidade e população, [...] ação vinculada, política, estratégia democratizante, metodologia, sinalizando para uma universidade voltada para os problemas sociais com o objetivo de encontrar soluções” por meio da pesquisa básica e aplicada, "visando realimentar o processo ensino-aprendizagem como um todo e intervindo na realidade concreta" (PLANO..., 2019).

De acordo com o modelo defendido pelo Fórum desde 1987 e consolidado no Plano Nacional de Extensão, a extensão é considerada parte indispensável do pensar e fazer universitários, está clara a defesa pela institucionalização dessas atividades, tanto do ponto de vista administrativo como acadêmico, o que implica a adoção de medidas e procedimentos que redirecionam a própria política das universidades. É dentro desse contexto que o Programa Trilhas Potiguares se torna uma política institucional de extensão da UFRN. Entendo-o como uma das estratégias para atingir as metas estabelecidas no Plano Nacional de Extensão.

Ao longo de duas décadas o Programa Trilhas Potiguares tem sofrido algumas alterações: de um grupo de professores, discentes e técnicos caminhando e procurando mapear as condições ambientais e de biodiversidade da região Nordeste passa a ser um Programa Institucional com chamadas por meio de editais públicos a fim de selecionar municípios do interior do $\mathrm{RN}$, com até 15.000 habitantes e que estejam interessados em projetos construídos de forma "solidária e votados para o desenvolvimento sustentável das comunidades, objetivando "melhorar a qualidade de vida da população com foco no desenvolvimento social" (UFRN, 2016).

As ações do Trilhas Potiguares são planejadas com base em diagnósticos e demandas levantadas durante a etapa de preparação e elaboração dos projetos de intervenção nas comunidades selecionadas. Essas atividades são desenvolvidas por docentes, discentes e técnicos com base na indissociabilidade entre ensino, pesquisa e extensão e na promoção da participação social em interlocução com os coordenadores locais dos municípios selecionados. 
De fato, durante a sua existência, o Programa Trilhas Potiguares "vem consolidando suas ações de forma integrada, inter-relacionada e contextualizada" (UFRN, 2016), priorizando o trabalho interdisciplinar, multiprofissional e transdisciplinar, envolvendo diversas áreas temáticas na comunidade e podendo ser considerado uma possibilidade inovadora de interiorização das ações de extensão, que vão além do foco pedagógico ou assistencialista. Concordamos com o Pró-Reitor Adjunto de Extensão quando afirma que

A prática extensionista possibilita a Universidade cumprir sua função social, estabelecendo sua relação intrínseca com a sociedade de forma a garantir e promover valores democráticos de igualdade e desenvolvimento social, através da difusão de novos conhecimentos e novas metodologias, possibilitando aos estudantes uma formação profissional, técnica e cidadã. A relação entre UFRN e as localidades selecionadas para o Programa é de grande relevância acadêmica e social, uma vez que possibilitará aos professores, técnicos e estudantes a ultrapassagem dos limites institucionais, assegurando maior inserção da academia na dinâmica das transformações sociais (UFRN, 2016).

Seguindo as origens dessa atividade de extensão - e acompanhando as mudanças paradigmáticas das Instituições de Educação Superior (IES) -, é possível perceber que já no primeiro ano do Programa Trilhas Potiguares [1996] estão delineadas as diretrizes do modelo de atividade extensionistas que se deseja concretizar.

Já nas primeiras edições do Trilhas realizada nos anos de 1996 a 1999, é nítida a preocupação de atender às demandas dos municípios. Assim, vejamos como se posiciona a coordenadora:

[...] a gente não chega como o governo com um programa pronto [...] pelo contrário, a gente tem reunião com o poder constituído, com as lideranças formais e informais da comunidade e, a partir do que eles nos colocam, da demanda que é passada para a gente, é que são desenvolvidas as atividades [...] é um trabalho participativo [...]. A gente trabalha muito em cima da demanda, pode até ser interesse do aluno desenvolver naquela área sua pesquisa, seu trabalho, o aluno se envolve e acaba levando aquele trabalho para dentro da sala de aula. Este é o papel das Trilhas: trazer para a sala de aula a realidade do estado e ver formas de transformar esta realidade (MEDEIROS, 2000 apud SOUSA, 2000, p. 90).

Esse discurso está em consonância com a racionalidade neoliberal de que as universidades enquanto organizações sociais devem prestar conta de seus serviços à comunidade. As universidades devem ser capazes de dar suporte à inovação e ao empreendedorismo, pois a nova razão do mundo exige cada vez 
mais de empreendedores no processo de inovação, como uma fonte crucial para que os negócios, as empresas e as pessoas possam crescer e se desenvolver (BONHEMBERGER; AUDY, 2018).

Concordamos com Dardot e Laval (2016, p. 326) quando escrevem que o "neoliberalismo pode ser definido como o conjunto de discursos, práticas e dispositivos que determinam um novo modo de governo dos homens segundo o princípio universal da concorrência”. Nesse passo, o papel das universidades dentro dos marcos do neoliberalismo valoriza a cultura empreendedora. Assim, o discurso da inovação, do empreendedorismo, da proatividade para a resolução de problemas, da ousadia para assumir riscos e aproveitar oportunidades, da postura e da cultura empreendedora cria ambientes favoráveis para que discentes e docentes desenvolvam seus conhecimentos como que motores de transformação (LEHDONVIRTA, 2013; ETZKOWITZ, 2013 apud BONHEMBERGER; AUDY, 2018, p.71).

Dessa forma, como asseveram Dardot e Laval (2016, p. 332), “a empresa torna-se não apenas um modelo geral que deve ser imitado, como também uma atitude que deve ser valorizada na criança e no aluno, uma energia potencial que deve ser solicitada no assalariado, uma maneira de ser que é produzida pelas mudanças institucionais".

De fato, o momento neoliberal "caracteriza-se por uma homogeneização do discurso do homem em torno da figura da empresa [...] porque o efeito procurado pelas novas práticas de fabricação e gestão do novo sujeito é fazer com que o indivíduo trabalhe para a empresa" e essa racionalidade deve ser aprendida no processo formativo. Entretanto, "isso não significa que a neogestão não seja novidade e o capitalismo no fundo seja sempre o mesmo", como nos alertam Dardot e Laval (2016, p. 326). Ao contrário, "a grande novidade reside na modelagem que torna os indivíduos aptos a suportar as novas condições que lhes são impostas" (DARDOT; LAVAL, 2016, p. 326-329). Tornando compreensível, dentro dessa racionalidade, que as atividades acadêmicas acompanhem essa tendência mundial, que convoca as universidades a assumirem o protagonismo no processo de desenvolvimento da sociedade.

Enfim, nos primeiros anos das Trilhas estava alicerçado o modelo de extensão que a UFRN iria defender e consolidar: atividade de extensão interligada às demandas da sociedade, priorizando metodologias participativas inseridas em um quadro de reestruturação dos Programas sociais implementados, que 
obedecem à lógica de políticas educacionais gerencialistas, descentralizadas, focalistas e privatizantes, nos marcos da racionalidade neoliberal.

\section{PROGRAMA TRILHAS POTIGUARES VINTE E TRÊS ANOS DEPOIS}

Passados vinte e três anos, as Trilhas Potiguares da UFRN se caracterizam como um "Programa de extensão" e "deve ser entendido como processo de articulação de ações de extensão, com clareza de diretrizes e orientação para um objetivo comum evidenciando abordagem sistêmica, interdisciplinaridade e multiprofissionalidade” (UFRN, 2019b).

O Programa é considerado "o maior Programa de Extensão Universitária” da instituição. Nesses 23 anos de existência, "atuou em 109 municípios" do estado do RN "e contou com a participação de 2.090 estudantes, 123 docentes e 30 técnicos devidamente registrados nos arquivos da PROEX/UFRN, mas estima-se que o Programa já atingiu cerca de 5.000 alunos" (FRAGA; VILLAR, 2017, p. 20).

A chamada para a participação no Programa Trilhas Potiguares se faz por meio de Editais nos quais são tornadas públicas as normas para a inscrição, a seleção e a participação dos municípios, dos professores e dos alunos interessados.

É possível ler no Edital $n^{\circ}$ 03/2018 as definições do que é "extensão universitária"; "programa de extensão", "projeto de extensão" e "Trilhas Potiguares". Assim, Trilhas Potiguares é compreendida como um "Programa de extensão com efetiva interação entre a Universidade e a comunidade de pequenos municípios do Rio Grande do Norte, com até 15.000 habitantes" (UFRN, 2019b).

A ação em cada município selecionado "constitui um Projeto de Extensão" cuja definição apresentada no Edital nos remete ao "conjunto de atividades acadêmicas, de caráter educativo, social, cultural, científico ou tecnológico". Porém, essas atividades devem cumprir "os preceitos da indissociabilidade entre ensino, pesquisa e extensão" e devem ser desenvolvidos "com integração no território e ou grupos populacionais, apresentando objetivo específico e prazo de execução determinado" (UFRN, 2019b). 
Cada projeto deve ser registrado no Sistema de Gestão de Atividades Acadêmicas da UFRN (SIGAA) na modalidade de Projeto de Extensão. Conforme item 4.1 do Edital 013/2018, cada projeto terá uma "Equipe Executora", que será composta por membros da UFRN (docentes, discentes e técnicos-administrativos) e membros da comunidade do município, podendo outras Instituições de Educação Superior (IES), mediante acordo, compor a equipe. Cada equipe será constituída de dois coordenadores do quadro da UFRN, 20 discentes dos diversos cursos de graduação, pós-graduação e técnico e os representantes dos municípios. O coordenador local é um morador do município indicado oficialmente pela Prefeitura para exercer a função de organizador da logística de execução das atividades, "inclusive intermediando a relação do Coordenador do Projeto com a Prefeitura do município".

Os Projetos que compõem o Programa Trilhas Potiguares são desenvolvidos em cinco etapas, são elas: a) inscrição e seleção de docentes, discentes e municípios; b) oficinas de demandas e potencialidades a serem tratadas pela equipe do projeto no município a partir de seleção, usando metodologias participativas; c) formação da Equipe e Planejamento das Atividades do Projeto; d) ação coletiva da Equipe do Projeto no Município, momento da vivência da equipe UFRN no município, com duração mínima de sete dias, a ser realizada em período determinado (junho ou julho); e) ação continuada no município a depender do acordo com a Prefeitura de cada município a ser realizado no segundo semestre letivo (UFRN, 2019).

Em 10 de agosto de 2015, houve o "primeiro seminário de avaliação do programa trilhas potiguares [...] visando ampliar as discussões acerca das ações do programa [...] e seus efeitos nos municípios". O referido seminário contou com a participação dos coordenadores dos municípios de Ielmo Marinho, Martins, Riachuelo, Elói de Souza, Sítio Nono e Vera Cruz, e ainda com os discentes "trilheiros", com a equipe da PROEX, com os docentes coordenadores e os bolsistas da UFRN.

O relato das principais dificuldades enfrentadas e as sugestões para as próximas edições revelam, de acordo com o documento intitulado "I Seminário de Avaliação do Trilhas Potiguares", que é necessário

[...] Efetuar ações punitivas aos desacordos por parte dos municípios, assim como de coordenadores e trilheiros; Cobrar um maior envolvimento dos representantes dos municípios, para que possam ofertar uma infraestrutura melhor para os trilheiros (principalmente 
transporte, alimentação e locais de hospedagem); Aplicação de questionário ao final do programa para municípios e coordenadores; Maior atenção para diagnosticar as demandas locais, tentando atingir áreas temáticas; Permitir que os alunos que participaram no ano anterior possam participar, no mínimo, de mais uma edição do programa, a conseguinte; Discutir a possibilidade dos coordenadores poderem voltar ao mesmo município no ano seguinte, permitindo, assim, um melhor diagnostico da perpetuação das ações e a continuidade das mesmas; Permitir que os segundos coordenadores possam ser escolhidos pelos próprios coordenadores de cada município (desde que sejam de cursos diferentes e estejam inscritos no edital); Procurar promover oficinas de longa duração (uma semana inteira), pois foi percebido que as mesmas surtem melhores resultados no município; Realização de ações anteriores à semana de realização do Trilhas, visando integração dos grupos e discussão dos reais objetivos; Focar ações em regiões determinadas no momento da seleção dos municípios; Discriminar melhor as atribuições dos municípios no contrato; Realizar inclusão nas equipes; Focar no trabalho voltado para os assentamentos; Realizar seminários prévios e de avaliação.

O documento de avaliação, conforme a citação anterior revela, focou basicamente em questões de infraestrutura e logística para "os trilheiros”. Pelo menos nesse Relatório, a avaliação quanto às possíveis articulações entre a atividade de extensão, o ensino e a extensão dos envolvidos não foi pontuada. Segundo afirma o Pró-Reitor Adjunto de Extensão da UFRN na apresentação do Relatório-Anuário de 2016,

Os relatórios apresentados pelos participantes foram fundamentais para a construção dos critérios atuais que permitiram aos gestores públicos sair da condição passiva, que se resumia à recepção das equipes da universidade, para uma atuação protagonista, onde ao final das atividades durante o ano os atores envolvidos sejam capazes de elaborar propostas capazes que possibilitem soluções a curto, médio e longo prazo para as demandas surgidas com propostas ou projetos que viabilizem alguma mudança de realidade na comunidade atendida. Espera-se ainda, que as experiências vivenciadas pelos alunos qualifiquem a sua formação acadêmica e cidadã podendo gerar produtos de utilidade pública.

Como se pode inferir, a preocupação com as demandas está fortemente presente nos discursos e nas práticas desenvolvidas no Programa, reforçando nossa compreensão de que há de fato a preocupação com a utilidade das ações de extensão desenvolvidas pelo Programa.

É inegável que os diversos projetos desenvolvidos pelas Trilhas produzem conhecimento e contribuem para a melhoria das condições de saúde e educação das populações visitadas. Entretanto, as técnicas de gestão usadas na execução dos projetos (especialmente, a normalização dos procedimentos) parecem 
inibir atitudes investigativas que sejam articuladas ao ensino e à pesquisa na medida que o atendimento das reivindicações das prefeituras das cidades visitadas torna-se o norte das ações, conforme as exigências previstas nos Editais.

Em que pese a importância de se desenvolver ações extensionistas com o objetivo de solucionar problemas regionais, me parece necessário não perder de vista o potencial inovador, científico-tecnológico da Universidade sob pena de torná-la uma "organização multifuncional e utilitária” como já apontavam Sousa e Yamamoto (2000, p. 58) na pesquisa realizada.

\section{CONSIDERAÇÕES FINAIS}

Revisitar o Programa Trilhas Potiguares 20 anos após concluir a pesquisa foi uma tarefa interessantes de ser feita, especialmente porque a "nova razão" do mundo parece estar mais evidente, pois como asseveram Dardot e Laval (2016, p. 7), "o novo governo dos homens penetra até em seu pensamento, acompanha, orienta, estimula e educa”. O que há vinte anos mais parecia um tipo de política econômica. Hoje está mais claro que é um "sistema normativo que ampliou sua influência ao mundo inteiro, estendendo a lógica do capital a todas as relações sociais e a todas as esferas da vida" (DARDOT;LAVAL, 2016,p.7).

De fato, o "panóptico de Bentham", erguido em glória de vigilância, molda as subjetividades e por mais que pensemos que estamos atuando na perspectiva de reforço da solidariedade e justiça social, ao que tudo indica, estamos reforçando o modelo para forjarmos os "homens úteis, dóceis ao trabalho, dispostos ao consumo" conforme Dardot e Laval (2016, p.332).

Assim, a fabricação do "homem eficaz" já começa a ser delineado no processo formativo e a Universidade não é mais o local da criação, da inovação ou da "pesquisa pura", cabe a essa instituição atender às inúmeras demandas da sociedade. Esse modelo geral que deve ser imitado e "valorizado na criança e no aluno" produz "mudanças institucionais", definindo uma nova ética, um "certo ethos que deve ser encarnado com um trabalho de vigilância sobre si mesmo e que os procedimentos de avaliação se encarregam de reforçar e verificar" como muito bem esclarecem os autores franceses (DARDOT; LAVAL, 2016, p.332).

Passadas duas décadas da pesquisa, sob a racionalidade neoliberal, assistimos perplexos o desprestígio das instituições de educação superior públicas e o avança das matrículas, mas IES privadas-mercantis. $\mathrm{O}$ produtivismo 
acadêmico acompanhado do adoecimento docente e a terrível demonização da identidade universitária como lugar da reflexão plural e da teoria.

O que me fez lembrar a postagem do Senador da República, eleito pelo Rio Grande do Norte, ao defender a escola cívico-militar. Ele escreveu no seu Twiter: "isso não é plano ou projeto, essa escola é real feita com trabalho e coragem de quem cansou da teoria ou doutorado em educação falida”.

Então, não é de se estranhar o discurso de que a Universidade deve atender às demandas das prefeituras, afinal a cobrança é por ações imediatas. Tudo implementado nos marcos da "neogestão", que não tem nada de antiburocrática, como nos esclarecem Dardot e Laval (2016). Na verdade, ela corresponde a uma nova fase, mais sofisticada, mais individualizada, mais competitiva da racionalização burocrática, dentro dessa "nova razão do mundo" (DARDOT; LAVAL, 2016, p. 330).

Certamente, a Universidade, por se tratar de uma Instituição social, não poderia escapar dessa racionalidade. Essa racionalidade impõe um tremendo desafio aos intelectuais porque não podemos nos contentar apenas com a crítica à mercantilização generalizada da vida, mas é preciso darmos uma resposta inédita à "governamentalidade neoliberal" (DARDOT; LAVAL, 2016).

Em que pese a impossibilidade de termos as mesmas concepções de extensão no interior do Programa, pois os sujeitos que estão dentro da Universidade espelham as divisões sociais, as diferenças políticas e os projetos culturais distintos, ou seja, a universidade é uma instituição social e, nessa qualidade, exprime a realidade social das suas divisões, das diferenças e dos conflitos da sociedade que está inserida, o que reflete nos diferentes projetos que compõem o Programa.

Contudo, se tratando de um Programa de Extensão longevo, são 23 edições, parece indispensável avaliá-lo no sentido de garantir que ele de fato exprima a articulação indissociável com o ensino e a pesquisa.

Finalizamos este artigo com a seguinte reflexão: como pretendemos enfrentar o descaso que estamos assistindo por parte do atual governo às Universidades públicas? Iremos reforçar sua identidade científica, tecnológica e inovadora ou insistiremos com o viés produtivista, utilitarista multifuncional?

Por ora, a UFRN, por meio do Programa Trilhas Potiguares, está atenta às necessidades demandadas na sua região. E o Programa Trilhas é terreno fértil para inspirar conhecimento, fomentar pesquisas, cultivar a solidariedade e 
fazer florir uma sociedade mais justa e igualitária ainda que refém da racionalidade em que está inserido.

\section{REFERÊNCIAS}

ANDRADE, Arnon A. M. Entrevista sobre o Programa Trilhas Potiguares. Natal, 1999. Entrevista concedida à mestranda Andréia da Silva Quintanilha Sousa em 8 dez. 1999. BONHEMBERGER, Marcelo; AUDY, Jorge Luis Nicolas. Universidade: a articulação entre inovação, extensão e empreendedorismo para o engagement estudantil. In: ZABALZA, Miguel B.; VITÓRIA, Maria Inês Côrte (Org.). Engagement na educação superior: conceitos, significados e contribuições para a universidade contemporânea. Porto Alegre: EDIPUCRS, 2018.

CARVALHO, Edilson Alves de. Sobre o Projeto "Pé na Trilha”. Natal, 1999. Entrevista concedida à mestranda Andréia da Silva Quintanilha Sousa em 15 dez. 1999.

FRAGA, Maria da Conceição; VILLAR, Ana Eugênia de Vasconcellos (Org.). Na trilha do Trilhas Potiguares. Natal: EDUFRN, 2017.

MEDEIROS, Márjorie da Fonseca e Silva. Sobre o Programa Trilhas Potiguares. Natal, 2000. Entrevista concedida à mestranda Andréia da Silva Quintanilha Sousa em 29 mar. 2000.

MELO NETO, José Francisco de. Extensão universitária: uma análise crítica. 1997. Tese (Doutorado em Educação) - Centro de Filosofia e Ciências Humanas, Universidade Federal do Rio de Janeiro, Rio de Janeiro, 1997.

PLANO NACIONAL DE EXTENSÃO UNIVERSITÁRIA. Disponível em: https://www. ufmg.br/proex/renex/images/documentos/Plano-nacional-de-extensao-universitaria-editado.pdf. Acesso em: 21 abr. 2019.

QUEIROGA, Bernadete Lourdes. Sobre o Projeto “Pé na Trilha”. Natal, 1999. Entrevista concedida à mestranda Andréia da Silva Quintanilha Sousa em 15 dez. 1999.

SOUSA, Andréia da Silva Quintanilha. Memória do programa "Trilhas Potiguares" de 1996 a 1999. 233p. Dissertação (Mestrado) - Centro de Ciências Sociais Aplicadas, Programa de Pós-graduação em Educação, Universidade Federal do Rio Grande do Norte, Natal, 2000.

SOUSA, Andréia da Silva Quintanilha; YAMAMOTO, Oswaldo Hajime. Programa Trilhas Potiguares: um modelo de extensão? Educação em Questão, v. 10 e 11, n. 2/1, jul./ dez. 1999, jan./jun., 2000.

TAVARES, Maria das Graças Medeiros. Extensão universitária: novo paradigma de universidade? Maceió: EDUFAL, 1997.

UNIVERSIDADE FEDERAL DO RIO GRANDE DO NORTE. Plano Estratégico de Ação 1995-1999. Natal: EDUFRN, 1995, 31 p. 
UNIVERSIDADE FEDERAL DO RIO GRANDE DO NORTE. Relatório de gestão: 1995-1999. Natal: EDUFRN, 1999.

UNIVERSIDADE FEDERAL DO RIO GRANDE DO NORTE. Trilhas Potiguares: Relatório 2016. Natal: UFRN, 2016. Disponível em: file:///C:/Users/marcis\%20base/ Desktop/PROGRESS\%C3\%830\%20FUNCIONAL/anuario_trilhas_2016.pdf. Acesso em: 01 maio 2019.

UNIVERSIDADE FEDERAL DO RIO GRANDE DO NORTE. Trilhas Potiguares: Relatório 2018. Organização de Breno Guilherme de A. Tinoco Cabral e Eriama de Araújo Hackradt. Colaboração de Adrieny de Paula Silva et al. 1. ed. Natal: UFRN, 2019a. Disponível em: file:///C:/Users/marcis\%20base/Desktop/PROGRESS\%C3\%830\%20 FUNCIONAL/anuario_trilhas_2018.pdf. Acesso em: 01 maio 2019.

UNIVERSIDADE FEDERAL DO RIO GRANDE DO NORTE. Edital nº 013/2018. Chamada pública para inscrição dos municípios no Programa Trilhas Potiguares - Edição 2019. Natal: Pró-Reitoria de Extensão, 2019b. Disponível em: file://C:/Users/marcis\%20 base/Desktop/Edital_Equipes_Trilhas_Potiguares_2019_Retificado.pdf. Acesso em: 29 abr. 2019.

UNIVERSIDADE FEDERAL DO RIO GRANDE DO NORTE. Trilhas Potiguares: primeiro seminário do Trilhas Potiguares. Disponível em: file://C:/Users/marcis\%20 base/Desktop/Relatorio_Seminrio_de_Avaliao_do_Trilhas_Potiguares.pdf. Acesso em: 01 maio 2019. 